\title{
- Complexity and simplicity in percutaneous bifurcation interventions: randomized controlled trials vs real-world data from real-life patients
}

\section{Deiti Prvulović'**, Martina Menegoni', Božo Vujeva', CKrešimir Gabaldo', Irzal Hadžibegović², Ognjen Čančarević}

'General Hospital „Dr. Josip Benčević", Slavonski Brod, Croatia

${ }^{2}$ University Hospital Dubrava, Zagreb, Croatia
RECEIVED:

February 2, 2018

ACCEPTED:

February 10, 2018

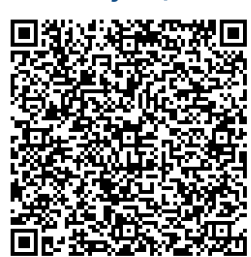

KEYWORDS: bifurcation lesions, provisional stenting, two-stent technique CITATION: Cardiol Croat. 2018;13(1-2):37. | https://doi.org/10.15836/ccar2018.37

*ADDRESS FOR CORRESPONDENCE: Đeiti Prvulović, Opća bolnica "Dr. Josip Benčević", A. Štampara 42, HR-35000 Slavonski Brod, Croatia. / Phone: +385-91-554-7188 / E-mail: deiti.prvulovic@gmail.com

ORCID: Đeiti Prvulović, https://orcid.org/0000-0002-8041-1197 • Martina Menegoni, https://orcid.org/0000-0002-4295-9039 Božo Vujeva, https://orcid.org/0000-0003-0490-3832 • Krešimir Gabaldo, https://orcid.org/0000-0002-0116-5929

Irzal Hadžibegović, https://orcid.org/0000-0002-3768-9134• Ognjen Čančarević, https://orcid.org/0000-0002-1285-8042

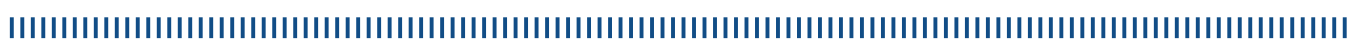

We can calculate that 2 million interventions worldwide are performed on bifurcation lesions per year. Publication of the $12^{\text {th }}$ consensus document from the European Bifurcation Club $(E B C)^{1}$ confirms that we are still looking for perfect bifurcation treatment. Analyzing eight general consensus statements and a number of consensus documents dedicated to specific topics published by EBC, the most important question in treating bifurcation lesion (BL) is the decision whether to implant one stent or two stents (simplicity or complexity). ${ }^{2}$ This decision depends mostly on the operator's subjective judgment of the true clinical relevance of a side branch.

We will review the present literature on how to differentiate simple from complex BL and critical analysis of clinical studies comparing provisional vs two stent techniques. We will present real world data from our medium volume center. We conclude and suggest:

1. our reality differs from randomized controlled trials (RCT): there is a disconnection between RCT and patient-centered decision-making;

2. EBC consensus is based on the data from RCTs done by top experts. The decision how to treat BL is largely based on the comfort and experience of the operator. Every day less experienced operators are faced with the challenge of treating complex bifurcation lesions in real world;

3. We need data in the standard of real-world clinical practice: detailed clinical data of the patient, anatomical lesion details, all of the details of the performed procedure and wide spectrum of clinical and angiographic outcomes.

These facts must be kept in mind in our search for holy grail in treating BL: technique that is fast, simple, easy, with less contrast and radiation, high success rates, low complications and good longterm results.

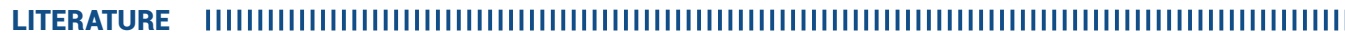

1. Lassen JF, Burzotta F, Banning AP, Lefèvre T, Darremont 0, Hildick-Smith D, et al. 1. Percutaneous coronary intervention for the left main stem and other bifurcation lesions: 12th consensus document from the European Bifurcation Club. Percutaneous coronary intervention for the left main stem and other bifurcation lesions: 12th consensus document from the European Bifurcation Club. Eurolntervention. 2018 Jan 20;13(13):1540-1553. https://doi.org/10.4244/EIJ-D-17-00622

2. Serruys PW. The treatment of coronary bifurcations: a true art form. EuroIntervention. 2015;11 Suppl V:V7. https://doi.org/10.4244/EIJV11SVA1 